\title{
Severe gas-forming necrotizing fasciitis of the right hip and thigh: Case presentation and review
}

\author{
Abdelkarim Waness* \\ Department of Medicine, New Care Clinic, Qatar
}

\begin{abstract}
Objective and importance: Extensive gas-forming necrotizing fasciitis is a life threatening soft tissue infection. It usually has a dramatic clinical presentation associated with severe complications. The objective of this presentation is to further raise awareness about this severe infection.

Clinical presentation: I am presenting a case of a diabetic bed-bound man with a large lateral thigh decubitus ulcer. He developed and survived a severe gas-forming necrotizing fasciitis of the right hip and thigh.

Intervention: The patient was treated with lengthy intravenous antibiotics course and repetitive aggressive surgical debridement.

Conclusion: Despite modern medical advancements, necrotizing fasciitis can still be encountered. While unsanitary military wounds are a classical set-up for this condition, iatrogenic interventions can also promote it. A variety of toxin-secreting micro-organisms can be implicated. Early antibiotic coverage and aggressive surgical debridement are keys in treating this potentially severe condition.
\end{abstract}

\section{Introduction}

Necrotizing fasciitis(NF) is an extreme form of soft tissue infections. Historically, it has a terrible reputation and still can have an ominous clinical presentation in modern days. Until the twentieth Century, it was responsible for hundreds of thousands of severe infections, disfiguring mutilations, and horrible deaths. Thankfully the incidence of necrotizing fasciitis has dramatically gone way down, its prognosis however remains poor.

\section{Case presentation}

Anelderly diabetic paraplegic man presented with fever, chills and diaphoresis for 5 days. His only medication was subcutaneous insulin therapy. On examination, the patient looked ill with dusky skin discoloration. Vital signs were: temperature: $38^{\circ} \mathrm{C}$, pulse: $113 \mathrm{bpm}$, RR: 23/min, BP: $87 / 53 \mathrm{~mm} \mathrm{Hg}$, and SPO2: $98 \%$ (on room air). $\mathrm{He}$ had a large right trochanteric ulcer measuring $5 \times 6 \mathrm{~cm}$ with necrotic base oozing foul-smelling purulent discharge. Palpation of the thigh revealed subcutaneous crepitation extending toward the right groin. Labs: WBC: $33.8 \times 10^{9} / \mathrm{L}$ (range $4.5-10 \times 10^{9} / \mathrm{L}$ ) with neutrophilia and bandemia, hemoglobin: $116 \mathrm{~g} / \mathrm{L}(117-155 \mathrm{~g} / \mathrm{L})$, platelets: $601 \times 10^{9} / \mathrm{L}$ $\left(140-400 \times 10^{9} / \mathrm{L}\right)$, glucose: $10.5 \mathrm{mmol} / \mathrm{L}(3.9-6.1 \mathrm{mmol} / \mathrm{L})$, sodium: $129 \mathrm{mmol} / \mathrm{L}(135-145 \mathrm{mmol} / \mathrm{L})$, potassium: $4.5 \mathrm{mmol} / \mathrm{L}(3.4-5.1$ $\mathrm{mmol} / \mathrm{L})$, bicarbonate: $21 \mathrm{mmol} / \mathrm{L}(22-29 \mathrm{mmol} / \mathrm{L})$, serum creatinine: $80 \mathrm{micromol} / \mathrm{L}$ (59 - $104 \mathrm{micromol} / \mathrm{L}$ ), serum lactic acid level: 4.8 $\mathrm{mmol} / \mathrm{L}$ and ionized calcium: $1.04 \mathrm{mmol} / \mathrm{L}$. The rest of his laboratory work-up, including liver functions, coagulation profile and urinalysis was unremarkable. Blood cultures were negative. Wound cultures grew anaerobic micro-organisms, methicillin-resistant Staphylococcus aureus (MRSA) and Pseudomonas aeroginosa.

A plain X-ray of the right hip and femur demonstrated extensive subcutaneous emphysema extending to the upper part of the leg anteriorly without evidence of bone or joint lesion (Figure 1). The patient was diagnosed with fulminant gas-forming necrotizing fasciitis of the right hip and thigh. He was started on broad spectrum antibiotic regimen (vancomycin, clindamycin, piperacillin+tazobactam) and was urgently taken to the operating room where he underwent extensive debridement and irrigation of the right thigh. A biopsy of the hamstring's fascia showed intense suppurative inflammation with focal gangrenous necrosis and mixed bacterial growth (Figure 2). Postoperatively, the patient was transferred to the Intensive Care Unit. He subsequently required several surgical debridement to salvage his right thigh and was kept on antibiotic therapy. After prolonged hospitalization, the patient had a PICC line inserted for outpatient antibiotic treatment and was discharged in stable condition.

\section{Discussion}

Thepathogenesis of necrotizing fasciitis (NF) is complex and not fully understood. It can be caused by a variety of micro-organisms including some that are gas-producing. These pathogens are ubiquitous in nature and can be part of the usual flora of the human gut. With opportune conditions, they can produce potent toxins causing local tissue necrosis and diffuse vascular collapse. Examples of such powerful toxins include: alpha-toxin, $\mu$-toxin and sialidases, produced by Clostridium perfringens. They have potent ability to degrade many tissues and microstructures [1]. The end-result is endothelial dysfunction, microvascular injury, and tissue anoxic necrosis. When

Correspondence to: Abdelkarim Waness, MD, FACP, Senior Consultant, Department of Medicine, New Care Clinic, PO Box 14353 - Doha, Qatar, E-mail: n4a1w@yahoo.com

Key words: necrotizing fasciitis, diabetes mellitus, decubitus ulcer, antibiotics, surgical debridement

Received: September 12, 2016; Accepted: September 26, 2016; Published: September 28, 2016 


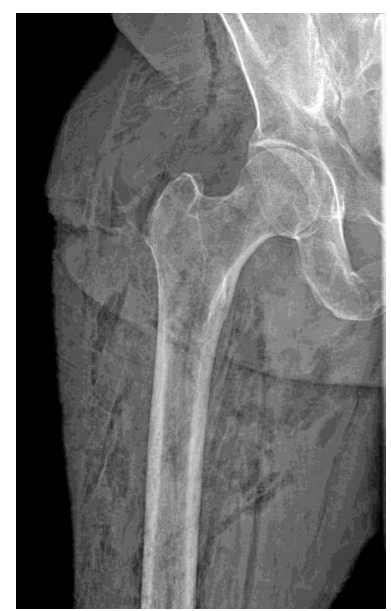

Figure 1. Right hip X-ray showing right trochanteric ulcer [arrowhead] with extensive soft tissue gas lucencies.

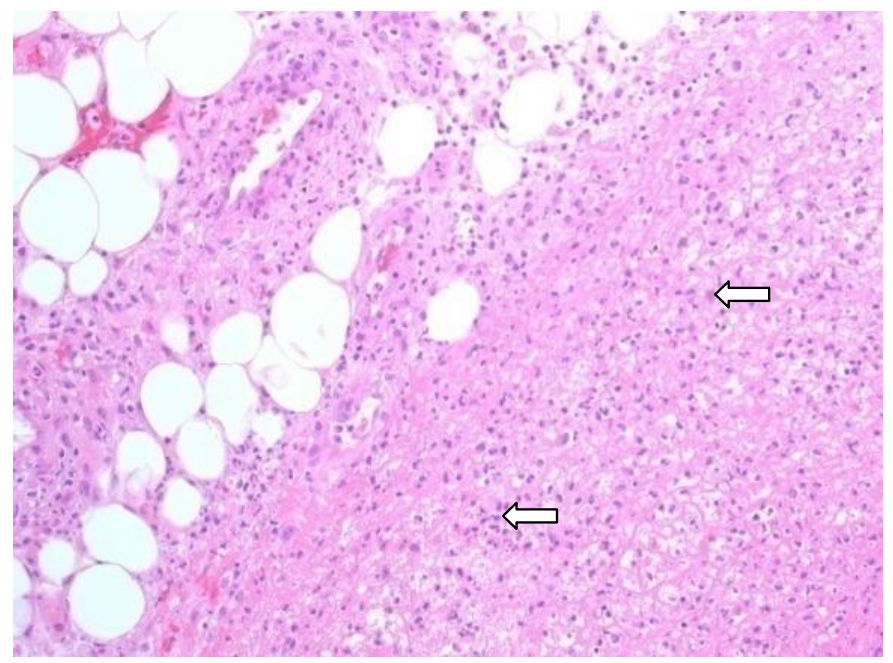

Figure 2. Hamstring's fascia biopsy showing marked infiltration of the soft tissue with mixed inflammatory cells predominantly neutrophils and histiocytes [arrows], with adjacent tissue necrosis and fibrinous exudation. Hematoxylin \& Eosin stain.

toxins reach arterial circulation, systemic shock and multi-organ failure follow.

The vast majority (90-95\%) of gas-producing infections is usually caused by clostridial species. They are gram-positive, anaerobic, sporeforming bacilli prevalent throughout nature especially in cultivated rich soil. More than 150 Clostridium species have been identified, however only few can cause fulminant infections. Among those: Clostridium perfringens, Clostridium novyi, Clostridium histolyticum, Clostridium bifermentans, Clostridium fallax, and Clostridium septicum: the latter might be associated with colonic malignancy in adults [2].

The remaining 5 to $10 \%$ of gas-forming soft tissue infections are caused by other microorganisms such as: Staphylococcus aureus, Streptococcus species, Pseudomonas aeruginosa and anaerobic microorganisms. In these rare forms of necrotizing fasciitis, cultures usually yield a polymicrobial etiology.

Necrotizing fasciitis has no apparent gender predilection. Pregnant or post-partum women can certainly suffer from this terrible infection [3]. It is encountered in all age groups from neonates to the elderly. Predisposing factors for gas-producing infection include traumatic injuries suffered during earthquakes or gun-shot wounds. Historically, military trauma was notoriously known for this dreaded condition. During World War I, around 100,000 German soldiers lost their lives as a result of traumatic gas gangrene [4]. These infections can also complicate modern surgical procedures, or burns [5]. Diabetics, such as this patient, are known to develop circulatory compromise, worsening denervation, and non-healing ulcerations. They are prone to both clostridial and non-clostridial NF with devastating consequences [6]. Other predisposing factors include: immunosuppression, alcohol and illicit drug abuse, or neglected homeless individuals. Few cases of "spontaneous" gas-producing necrotizing fasciitis have been described in the literature.

Classification of necrotizing soft tissue infections is done according to either microbial etiology, depth of infection (from adipositis to fasciitis to myositis), or to anatomical location [7]. Lower extremities are classical location for such infections; upper extremities' involvement is increasingly encountered because of intravenous manipulations and iatrogenic procedures.Other possible locations include abdominal wall or pelvic region [8].

Symptoms of necrotizing fasciitis vary. Fever, chills, diaphoresis are often witnessed and patients can look septic. The affected limb can be swollen, eryhematous or violaceous in color; with occasional presence of bullae, pus-oozing ulcers, or necrotic wounds. Palpation of the skin can reveal local tenderness, induration and often a peculiar cushioning-feel of subcutaneous crepitus (which is not always present). The infection can rapidly spread to deeper structures causing myonecrosis [9].

It is common to observe leukocytosis, electrolyte disturbances, or stigmata of acute renal injury. Blood cultures are routinely collected in septic patients but not always helpful. Different scoring systems have been proposed for necrotizing soft tissue infections. In a retrospective study, Wall et al found that mortality can be predicted in necrotizing fasciitis patients' having a WBC count higher than $30 \times 10^{9} / \mathrm{L}$ on admission. Wong and colleagues developed a scoring "Laboratory Risk Indicator for Necrotizing Fasciitis". If greater than 6, it might facilitate necrotizing fasciitis detection [10,11]. Helpful they might be, these laboratory indicators still lack validation from large well-designed prospective studies.

Radiologic adjuncts can be helpful in the diagnosis of gasproducing necrotizing fasciitis. Plain X-rays can identify subcutaneous emphysema or identify air-fluid level in cases of abscess or anatomical space containing gas and fluid. Ultrasonography is neither sensitive nor specific to reliably diagnose soft tissue infections. Computerized tomography has better sensitivity. It can show evidence of inflammatory changes such as edema or thickening of the fascia. Magnetic Resonance Imaging has excellent sensitivity (90-100\%) but modest specificity [12].

The diagnostic gold standard for necrotizing fasciitis remains the intra-operative biopsy of the infected tissues during surgical exploration. Findings include purulent or foul-smelling discharge, loss of normal fascia integrity, or obvious tissue necrosis accompanied by lack of bleeding involving subcutaneous tissues or adjunctive muscular structures [13].

Two major therapeutic pitfalls can be observed when dealing with necrotizing soft-tissue infections. They are: late diagnosis and inadequate surgical debridement. A broad spectrum empiric antibiotic regimen must be promptly started in order to initially cover for grampositive and anaerobic organisms. Beta-hemolytic streptococci remain 
the most common micro-organisms encountered with necrotizing soft tissue infections [14]. Methicillin-resistant Staphylococcus aureus (MRSA) seems to be an emerging etiologic agent however [15]. Aggressive surgical debridement is the next immediate important cornerstone in the management of these severe infections. Recurrent debridement and even limb amputation might be needed in some cases [16]. Some authors advocate the use hyperbaric oxygen therapy to possibly improve limb preservation chances [17].

Poor prognostic factors for necrotizing fasciitis include: gas formation, deep myonecrosis, and streptococcal toxic shock syndrome. Mortality remains relatively high (12 to $21 \%$ ) despite all therapeutic interventions $[18,19]$.

\section{Conclusions/Take home messages}

1- Necrotizing fasciitis has notoriously bad historical reputation. It still can be encountered nowadays despite modern medical advancements

2- Clostridial species are the predominant gas-forming pathogens in necrotizing fasciitis

3- Injuries suffered in military conflicts or major catastrophic events might facilitate the occurrence of this worrisome condition

4- High index of suspicion must be maintained for necrotizing fasciitis with appropriate early aggressive medical and surgical interventions

5- Complications, such as decubitus ulcer, must be addressed with early effective preventive measures before major complication such as NF ensues.

\section{References}

1. Adams JJ, Gregg K, Bayer EA, Boraston AB, Smith SP (2008) Structural basis of Clostridium perfringens toxin complex formation. Proc Natl Acad Sci U S A 105: 12194-12199. [Crossref]

2. Mischke A, Besier S, Walcher F, Waibel H, Brade V, et al. (2005) Spontaneous gas gangrene in a diabetic patient with Clostridium septicum. Chirurg 76: 983-986. [Crossref]

3. Gallup DG, Freedman MA, Meguiar RV, Freedman SN, Nolan TE (2002) Necrotizing fasciitis in gynecologic and obstetric patients: a surgical emergency. Am J Obstet Gynecol 187: 305-310.[Crossref]
4. Pailler JL, Labeeu F (1986) [Gas gangrene: a military disease?]. Acta Chir Belg 86: 63-71. [Crossref]

5. Davies DM (1979) Gas gangrene as a complication of burns. Scand J Plast Reconstr Surg13: 73-75. [Crossref]

6. Ghosh S, Bal AM, Malik I, Collier A (2009) Fatal Morganellamorganiibacteraemia in a diabetic patient with gas gangrene. J Med Microbiol 58: 965-967.[Crossref]

7. Sarani B, Strong M, Pascual J, Schwab CW (2009) Necrotizing fasciitis: current concepts and review of the literature. J Am Coll Surg 208: 279-288.[Crossref]

8. Agaba EA, Kandel AR, Agaba PO, Wong LS (2010) Subcutaneous emphysema muscular necrosis, and necrotizing fasciitis: an unusual presentation of perforated sigmoid diverticulitis. South Med J 103:350-2.[Crossref]

9. Sada A, Misago N, Okawa T, Narisawa Y, Ide S, Nagata M, et al. (2009) Necrotizing fasciitis and myonecrosis "synergistic necrotizing cellulitis" caused by Bacillus cereus. J Dermatol 36:423-6. [Crossref]

10. Wall DB, de Virgilio C, Black S, Klein SR (2000) Objective criteria may assist in distinguishing necrotizing fasciitis from nonnecrotizing soft tissue infection. Am J Surg 179: 17-21.[Crossref]

11. Wong CH, Khin LW,Heng KS, Tan KC, Low CO (2004) The LRINEC (Laboratory Risk Indicator for Necrotizing Fasciitis) score: a tool for distinguishing necrotizing fasciitis from other soft tissue infections. Crit Care Med 32: 1535-1541. [Crossref]

12. Schmid MR, Kossmann T, Duewell S (1998) Differentiation of necrotizing fasciitis and cellulitis using MR imaging. AJR Am J Roentgenol 170: 615-620.[Crossref]

13. Paramythiotis D, Koukoutsis H, Harlaftis N (2007) Necrotizing soft tissue infections. Surg Practice 11:17-28.

14. Khanna AK, Tiwary SK, Kumar P, Khanna R, Khanna A (2009) A case series describing 118 patients with lower limb necrotizing fasciitis. Int J Low Extrem Wounds 8: 112-116. [Crossref]

15. Miller LG, Perdreau-Remington F, Rieg G, Mehdi S, Perlroth J, et al. (2005) Necrotizing fasciitis caused by community-associated methicillin-resistant Staphylococcus aureus in Los Angeles. N Engl J Med352:1445-53. [Crossref]

16. Angoules AG, Kontakis G, Drakoulakis E, Vrentzos G, Granick MS, et al. (2007) Necrotising fasciitis of upper and lower limb: a systematic review. Injury 38: S19-26. [Crossref]

17. Hassan Z, Mullins RF, Friedman BC, Shaver JR, Brandigi C, et al. (2010) Treating necrotizing fasciitis with or without hyperbaric oxygen therapy. Undersea Hyperb Med 37: 115-123.[Crossref]

18. Rieger UM, Gugger CY, Farhadi J, Heider I, Andresen R, Pierer G, et al. (2007) Prognostic factors in necrotizing fasciitis and myositis: analysis of 16 consecutive cases at a single institution in Switzerland. Ann Plast Surg 58:523-30. [Crossref]

19. Peer SM, Rodrigues G, Kumar S, Khan SA (2007) Aclinicopathological study of necrotizing fasciitis--an institutional experience. $J$ Coll Physicians Surg Pak 17: 257 260.[Crossref]

Copyright: (C2016 Waness A. This is an open-access article distributed under the terms of the Creative Commons Attribution License, which permits unrestricted use, distribution, and reproduction in any medium, provided the original author and source are credited. 